\title{
Author Correction: The foundations of immune checkpoint blockade and the ipilimumab approval decennial
}

Alan J. Korman (1), Sarah C. Garrett-Thomson and Nils Lonberg (1)

Correction to: Nature Reviews Drug Discovery https://doi.org/10.1038/s41573-021-00345-8, published online 22 December 2022.

References 250 and 251 have been replaced to cite the correct statements.

https://doi.org/10.1038/s41573-022-00393-8 I Published online 14 January 2022

(c) Springer Nature Limited 2022 